Como romper com uma visão de ciência sem conhecê-la adequadamente? Meu temor reside em que ao pensar inovações como ruptura paradigmática, caminho que tenho trilhado, tenhamos rompido com a clareza de nossa comunicação. Receio que possamos estimular nos docentes, em formação, uma confusa visão da sociedade, da educação e do seu papel nela.

Por outro lado, aceitar a contradição entre formas de conhecer e produzir saberes, entre pensamentos únicos e pensamentos plurais, significa trabalhar sobre uma linha de fronteira. A meu ver, para a produção do novo importa a clareza com a qual atravessamos as fronteiras e se o fazemos junto com nossos alunos. Ao final, as inovações buscadas podem não ser... assim tão novas. Inovador terá sido caminhar fazendo o caminho.

É preciso clareza também para perceber que as inovações estão situadas na linha de tensão entre saberes e poderes. Na prática da sala de aula, da universidade, dentro do sistema de ensino tal qual como na sociedade, revelam-se poderes desiguais. E, a poderes desiguais correspondem saberes desiguais, perpetuando a escala da reprodução social com a qual todos nós podemos estar seriamente comprometidos.

Vejo que o texto de Cunha tentou mostrar a necessidade de uma "tessitura paciente de esforços e energias" para trabalhar com inovações pedagógicas no seu sentido pleno, o sentido de "um conhecimento prudente para uma vida decente." Com esta convicção, volto ao início do texto para reafirmar, com a autora, que as inovações estão mais próximas de nós do que imaginamos. O sinal de sua presença está em toda prática ou iniciativa pedagógica que possa reconfigurar, ou seja voltar a dar forma, feitio, ou reconformar tanto os poderes quanto os saberes que estão em circulação na sala de aula, na universidade, na sociedade. Afinal, parece elementar, mas, democracia também se constrói dessa forma, no coletivo, no confronto e nas tensões entre saberes e, principalmente, entre poderes. Possibilidade de produção para a qual o texto nos alerta.

\title{
Inovacción/esperanza...
} Innovation/hope...

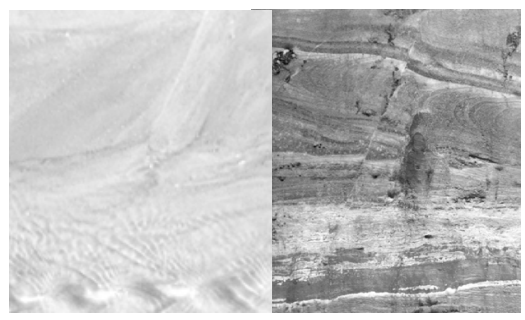

Elisa Lucarelli ${ }^{1}$

María Isabel da Cunha termina su significativo artículo sobre innovaciones pedagógicas invitándonos a hacer una profesión de fe en las posibilidades que tiene el ser humano para transformar el statu quo vigente en las aulas, en nuevas prácticas superadoras de la inercia que muchas veces caracteriza a la vida de las instituciones educativas.

Este mensaje de esperanza es síntesis de la intencionalidad que se encarna en este artículo de Cunha, y que se expresa en una articulación de conocimiento y afecto, pensamiento y acción, enfoque sólidamente basado en pilares epistemológicos, sociológicos, políticos y didácticos portadores también de un concepto contextualizado de innovación.

¿Cuál es el propósito que anima a la autora a abordar un objeto tan cuestionado, por sus connotaciones históricas recientes, como es el de innovación? ¿Cómo trasciende el estigma tecnicista que tiñe este tema para desarrollar un pensamiento propio y transgresor acerca de las innovaciones?

Cunha asume el compromiso educativo y da a sus reflexiones la misión de ser un agente analítico [también un analizador, dirían los institucionalistas] para la comprensión de las políticas educativas actuales, a la vez que una forma para concentrar energías para la resistencia. Nuevamente pensamiento y acción, reflexión e intervención. ¿Y no son estos los ejes estructurantes de una ciencia pedagógica crítica?

1 Professora, Universidade de Buenos Aires, UBA. <elisalucarelli@arnet.com.ar> 


\title{
DEBATES
}

Desde ese lugar, los referentes teóricos que sustentan al artículo expresan también la mirada multidimensional propia de estas perspectivas: Boaventura de Sousa Santos alerta sobre el peligro de una ceguera epistemológica y valorativa, consecuencia obligada del pensamiento único, a la vez que abre las puertas, esperanzadamente, a las innovaciones en los espacios educativos como una expresión de la ruptura que supone la transición paradigmática. Tardiff aporta a la construcción de una nueva concepción educativa, cuando enfatiza que formar no es transmitir el mensaje hegemónico sino enseñar a hacer elecciones. Freire permite que la autora encuentre en la energía emancipatoria presente siempre en educación las formas para articular subjetividades y para derivar en prácticas que recuperen la naturaleza inventiva y contradictoria del hombre.

En el artículo se sostienen conceptos que reivindican a la innovación desde un ángulo opuesto al enarbolado por la perspectiva tecnicista en educación. Las innovaciones que atraviesan lo didáctico y lo curricular (esto es el corazón de las instituciones educativas) se presentan como expresión de un proceso creativo y de interrupción del devenir habitual de las formas de enseñanza y evaluación; son producciones originales para su contexto de realización, gestadas y llevadas cabo por sujetos educativos a lo largo de todo el proceso. En este sentido son protagónicas: sus creadores, al igual que en el teatro griego, son los personajes principales de la acción y toman parte en los momentos significativos de esas prácticas.

Protagonismo y contextualización son también, a mi criterio, los principios de los que se vale Cunha para enfatizar la intencionalidad política de sus reflexiones al denunciar la contradicción presente en los programas que atravesaron (y a atraviesan aún hoy) los sistemas educativos de nuestro sur, programas que dicen orientarse hacia la mejora de la calidad educativa y desarrollan propuestas de evaluación con patrones homogenizadores de esa calidad. La metáfora de la frontera y de las márgenes del río, presente en el planteo de la transición paradigmática, abre posibilidades para que los sujetos del aula desarrollen prácticas que les permitan navegar en la innovación transformadora.

\section{Inovação/construção do conhecimento}

\author{
Innovation/building of knowledge
}

Gaudêncio Frigotto ${ }^{1}$

O texto de Cunha revela a acuidade de uma intelectual atenta aos dilemas e impasses de nosso tempo histórico e a compreensão de que os processos de construção do conhecimento e os processos educativos estão vinculados às práticas sociais. De imediato se situa, de forma clara, na perspectiva da não neutralidade do conhecimento e das práticas pedagógicas. Em sociedades cindidas por interesses de classe ou frações de classe, as teorias e as práticas educativas são produzidas dentro de determinadas visões de mundo e articulam ou reproduzem a manutenção da ordem estabelecida ou se afirmam na desarticulação e transformação da mesma.

O foco da análise centrado na crítica à atual tendência da "visão única", da padronização e da homogeneização abstrata da construção do conhecimento capta um dos problemas centrais da teoria social e da teoria educacional e suas conseqüências em termos de concepção pedagógica. No plano mais amplo, a visão única está vinculada à tese de Francis Fukuyama do fim da história, cuja mensagem letal é de que a única alternativa para a produção da vida humana efetiva-se sob as relações sociais capitalistas por tratar-se de uma

${ }^{1}$ Professor, Universidade Federal Fluminense, UFF, RJ. <gfrigotto@globo.com> 